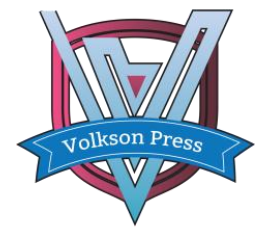

\author{
Contents List available at VOLKSON PRESS \\ Mechanical and Control Engineering (MCE) \\ DOI : http://doi.org/10.26480/wsmce.01.2017.125.126
}

\title{
DESIGN OF CLASSROOM ZONING LIGHTING CONTROL SYSTEM BASED ON MICROCONTROLLER
}

\author{
Teng Haikun*, Liang Xinxin, Jiang Yibin \\ Computer and Information Engineering College, Heihe University Academic Road No. 1, Heihe City, China. \\ *Corresponding Author Email: thk_1983@163.com
}

This is an open access article distributed under the Creative Commons Attribution License, which permits unrestricted use, distribution, and reproduction in any medium, provided the original work is properly cited

\section{ARTICLE DETAILS}

\section{Article History:}

Received 02 october 2017 Accepted 06 october 2017 Available online 11 november 2017

Keywords

District lighting, single chip microcomputer, sensor

\section{ABSTRACT}

Aiming at the problem of serious waste of classroom lighting electricity, put forward a design scheme of single chip microcomputer classroom area lighting control system based on the system, according to the people, light and other factors, regional intelligent control of the classroom lamp, to the effect of energy saving. When detected in the classroom, to detect light intensity, if the light position is weak, according to the position of light is located in this region of the light, otherwise remains out; according to the different requirements of the light intensity of the individual, through the manual way to control the status of the lamp; when people leave the classroom, the system will automatically the lights went out.

\begin{abstract}
1. Introduction
The great success of the second industrial revolution in the UK ushered in the "electric age" of mankind. China's reform and opening up enabled the electric equipment to enter China and rapidly promote its use. The increase in the use of electrical equipment increases the demand for electricity, resulting in waste. China proposes a sustainable development strategy, saves resources, and reduces the electricity load and demand for electricity. According to the statistics, China's colleges and universities are using manual switches, and even strengthening the management of electricity consumption can't avoid the waste of electricity consumption [1]. In order to solve the above problem, this paper presents a subregional intelligent lighting control system, the lighting points regionalization, convenient for management of the school, and more efficient to achieve the purpose of energy saving and environmental protection.
\end{abstract}

This article points the area light emitting light intensity control system by Risym photosensitive resistance sensor signal, the induction light intensity, reoccupy HR-SR501 human body IR sensor signal, the induction signal whether there is in the classroom the human body [2]. Again in the case of a certain someone would carry this information by the analog-to-digital conversion of single chip microcomputer to control center by setting control program for lighting intelligent control system using electrical appliances, only in dark and light to launch lighting system under the condition of existence of the human body, which in turn is controlled by a STC89C52 MCU emission light signal and the signal to the relay and liquid crystal display [3].Cut off the lighting circuit when the two sides are not active or when the natural light Intensity is high. The overall block diagram of the system is shown in the figure 1 .

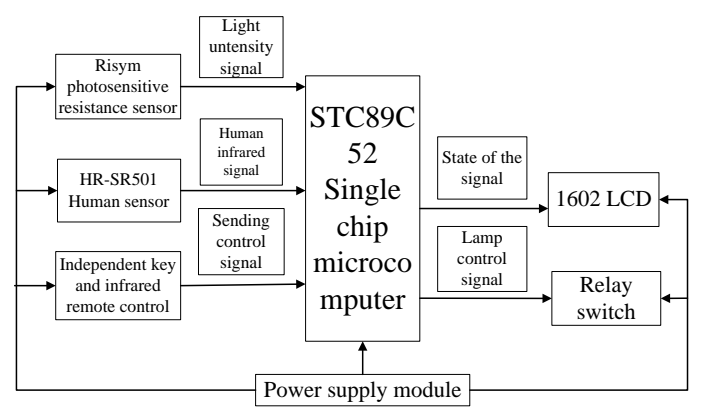

Figure 1: The System Block Chart

\section{THE SYSTEM DESIGN}

In this control system, HR-SR501 human induction sensor is used to detect the emission of thermal-emission infrared signal in the room and transfer to the single chip. At the same time, the trigger Risym photosensitive sensor to detect the current indoor light intensity, through conversion chip conversion to a single chip microcomputer, which judge the strength of light intensity, if light intensity is lower than the initial value, when the microcontroller to lighting control circuit signal control, open the indoor lighting [4].

Central Control Module. Single chip microcomputer to first initialized modulus conversion chip, when visible light detection component to the light intensity reaches preset values, by transmitting data conversion chip microcontroller, single-chip computer to store the information; Through the thermal release sensor and the processing circuit, whether there are human beings in the classroom, and the information data is sent to the single chip, the single chip can store the information; When the intensity of illumination and the two conditions in the teaching room meet the requirements of the single chip, the SCM sends out the control signal to turn on the indoor lighting. But this system itself is designed to save energy so need to choose the type of microcontroller low power consumption, and on STC microcontroller has fast speed, high reliability, low power consumption, and low price, so the system chooses STC89C52 as main control processor control.

HR-SR501 Human Induction Module. HC - SR501 is automatic control module based on infrared technology, using the German original installation import LHI778 probe design, high sensitivity, reliability, low voltage work mode, is widely applied in all kinds of automatic induction electrical equipment, especially a battery-powered automatic control product.

It has automatic induction: the person enters its induction range and the output is high level. The person leaves the induction range automatically delays the high level and the output is low; Temperature compensation: when the environment temperature in summer to $30 \sim 32{ }^{\circ} \mathrm{C}$, detection range is a bit shorter, as a certain performance compensation; Two trigger modes; a、non-repeatable trigger mode: The output will automatically change from high level to low level after the induction output is high level. b、 repeatable trigger mode: After induction output high level, the time delay period, if there is the human body in the scope of its induction activities, its output will always keep a high level, and it was not until after 
the people left the delay will be high level to low level. The induction range and external circuit diagram are shown in figure 2 below.
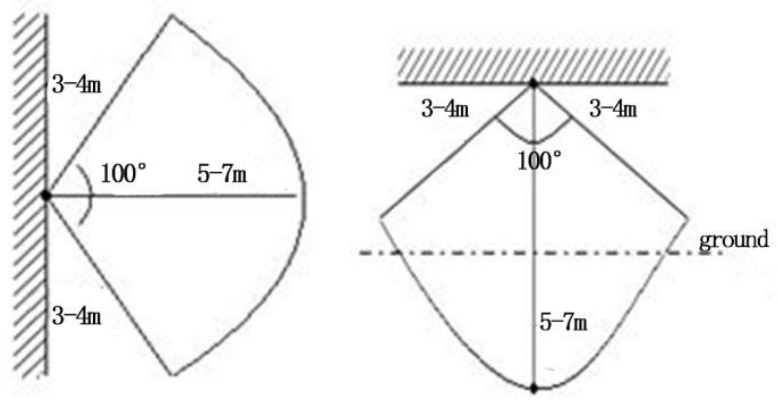

Figure 2: Induction Range

Risym Photosensitive Resistance Module. Used in the production of photosensitive sensor as visible photosensitive resistance, through the photosensitive resistance to visible light intensity is not at the same time its resistance is different, and the voltage change with the light intensity change, but it is only by single-chip analog voltage change cannot compatible with modulus conversion chip, so will send the signals to single chip microcomputer. Figure 3 shows the circuit diagram of photosensitive resistance principle.

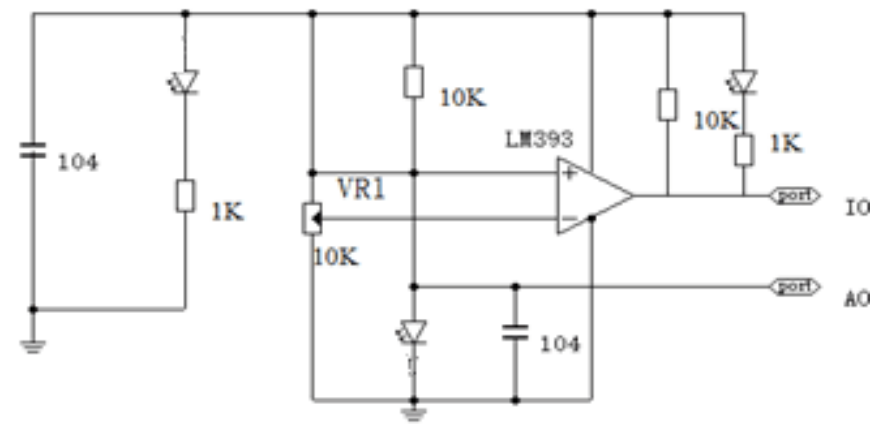

Figure 3: Circuit diagram of photosensitive resistance principle

\section{THE SOFTWARE DESIGN}

Firstly, the chip is initialized first, then the photosensitive element takes the illumination parameter, and the given numerical comparison returns the reacquisition if the illumination parameter is larger than the set parameter. If less than, wait for infrared detection whether someone, if someone sends out the interrupt and detect the location of the person, the procedure judge lighting the light and photograph the area; If no man returns; Systematic periodic detection is not a person, system control process flow chart is shown in figure 4 [5].

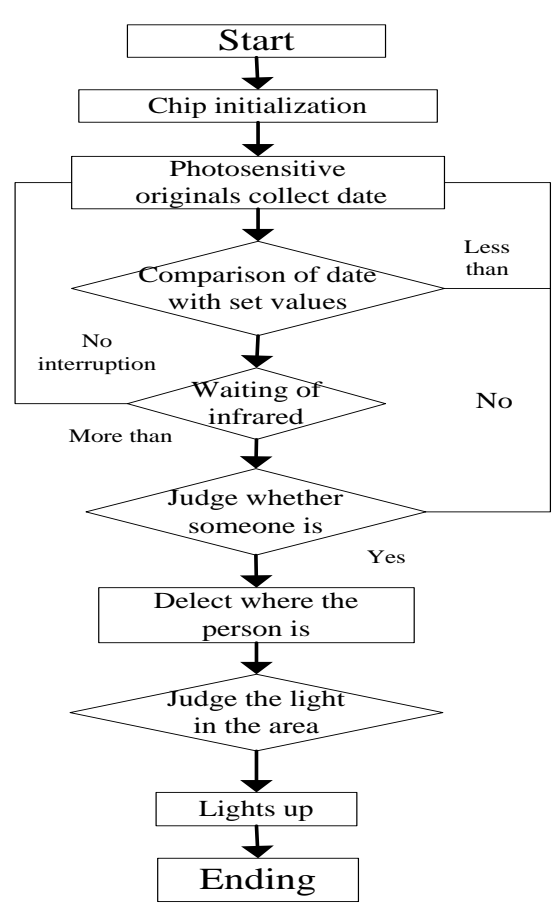

4. CONCLUSION

Figure 4: The Program Flow Chart

Lighting energy saving is a green environmental practice project, its meaning is more far-reaching, has broad development space. Described in this article the classroom area lighting control systems, schools and other places of large indoor lighting intelligent control, can effectively to the classroom lighting intelligent control areas, reducing waste of electric energy, improve the utilization rate of resources.

\section{ACKNOWLEDGEMENT}

2017 Heilongjiang University Students' Innovation and Entrepreneurship Training Program Project (ID: 201713744018).

\section{REFERENCES}

[1] Xiaorong, C., Rong, H. 2015. A lighting control system device based on DDC [J]. Experimental technology and management, 1 (1), 1-16.

[2] Kang, Z., Wenbin, Z., Shuai, L. 2016. Design of classroom smart lamp control system based on STM32 [J]. Internet of things technology, 2 (1), 4956.

[3] Shiyun, W. 2016. Design of energy-saving intelligent control system for classroom lighting based on single chip microcomputer [J]. Electronic design engineering, 11 (2), 2869-2900.

[4] Shen, G., Yinmao, S. 2015. Building lighting energy-saving control technology [J]. Science and technology innovation and productivity, 5 (1), 45-56.

[5] Liang, W., Ruihua, Z. 2015. Design of intelligent lighting control management system of teaching building [J].Modern electronics technology, 1 (9), 25-49 